\title{
Competition Effects in Phonological Priming: The Role of Mismatch Position between Primes and Targets
}

\author{
Sophie Dufour · Ronald Peereman
}

Published online: 17 March 2009

(C) Springer Science+Business Media, LLC 2009

\begin{abstract}
In three experiments, we examined lexical competition effects using the phonological priming paradigm in a shadowing task. Experiments $1 \mathrm{~A}$ and $1 \mathrm{~B}$ showed that an inhibitory priming effect occurred when the primes mismatched the targets on the last phoneme (/bagar/-/bagaj/). In contrast, a facilitatory priming effect was observed when the primes mismatched the targets on the medial phoneme (/viraj/-/vilaj/). Experiment 2 replicated these findings with primes presented visually rather than auditorily. The data thus indicate that the position of the mismatching phoneme is a critical factor in determining the competition effect between prime and target words.
\end{abstract}

Keywords Phonological priming $\cdot$ Lexical competition · Bottom-up inhibition

It is now widely accepted that as listeners attend to a spoken word, similar sounding words are activated and compete for recognition. Compatible with this assumption, numerous studies have shown that the recognition time for a spoken word is strongly influenced by the set of activated candidates from which the target word must be discriminated (see Frauenfelder and Peters 1998 for a review). For example, the recognition time for spoken words is affected by the number and frequency of other words with which they are phonologically similar (Luce et al. 1990).

S. Dufour

Laboratoire de Psycholinguistique Expérimentale, Université de Genève, Genève, Switzerland

S. Dufour $(\varangle)$

Laboratoire Parole et Langage (LPL) \& CNRS, Université Aix-Marseille, 5, Avenue Pasteur,

13100 Aix-en-Provence, France

e-mail: Sophie.Dufour@univ-provence.fr

R. Peereman

Université de Bourgogne, LEAD \& CNRS, Dijon, France

R. Peereman

Université Pierre Mendes-France, LPNC \& CNRS, Grenoble, France 
Models differ however about the precise mechanism by which competition is supposed to arise. In models such as TRACE (McClelland and Elman 1986) and Shortlist (Norris 1994), lexical competition is due to intra-level inhibition that operates between activated lexical candidates. By this mechanism, the target word tries to inhibit its competitors, but the competitors themselves also send inhibition to the target word and thus reduce its activation level, causing slower recognition. In contrast, in the Cohort (Marslen-Wilson 1987; Marslen-Wilson et al. 1996) or the NAM (Neighborhood Activation Model; Luce et al. 1990) models, competitors have no direct influence on the activation level of a target word. Lexical competition takes place only at the decision stage of recognition where the presence of close competitors slows down the process of discrimination among lexical candidates. For example, in the Cohort model, recognition occurs when the difference in activation between the target word and its most highly activated competitor reaches a fixed value. Hence, a competitor can influence the recognition of a target word by delaying the moment at which the target word can be reliably identified. Note that distinguishing between these two approaches has proven difficult. Indeed, an implementation of lexical competition in terms of lateral inhibition or decision rule often leads to very similar predictions (see Bard 1990).

An interesting way to study the competition process consists in measuring target performance after the presentation of one of its lexical competitors. What makes the phonological priming paradigm a useful tool for the study of lexical competition is that a competitor is explicitly presented and its effect on the subsequent processing of the target word can be measured. Although previous reports of phonological priming have provided conflicting results (Radeau et al. 1989; Slowiaczek et al. 1987; Slowiaczek and Pisoni 1986), more recent studies controlling both the amount of overlap between primes and targets and the contribution of strategic factors have shown that the time taken to identify a target word is delayed when it is preceded by a phonologically related prime, namely by one of its competitors (Dufour and Peereman 2003a,b; Hamburger and Slowiaczek 1996; Monsell and Hirsh 1998; Radeau et al. 1995; Slowiaczek and Hamburger 1992). The observation of an inhibitory priming effect is compatible with all the competitive activation models which predict that priming a target word by one of its competitors should delay its recognition. Indeed, preactivation of the competitor should increase its inhibitory influence during target processing in models such as TRACE (McClelland and Elman 1986) and Shortlist (Norris 1994). It should also take longer for the activation level of the target word to exceed that of its competitors in the Cohort model (Marslen-Wilson 1987; Marslen-Wilson et al. 1996). Note that the inhibitory influence of the prime is exerted only when it shares the first phonemes with the target word. When the primes and the targets overlap by their final phonemes but do not share the onset, facilitation is generally observed (Chéreau et al. 2007; Dumay et al. 2001; Monsell and Hirsh 1998; Norris et al. 2002; Radeau et al. 1995, 1998; Slowiaczek et al. 2000; Spinelli et al. 2001).

\section{What Evidence for Competition Effects in Phonological Priming?}

Using monosyllabic words and the shadowing latencies as a measure, Slowiaczek and Hamburger (1992) reported inhibitory priming effects when primes and targets share the first three-phonemes (e.g., grief-green) but not when they share the first one- (e.g., goalsgreen) or two-phonemes (e.g., grope-green). In order to determine the locus of the inhibition effect, Slowiaczek and Hamburger manipulated both the lexicality (word/non-word) and the modality (auditory/visual) of the primes. The inhibition in case of a three-phoneme overlap was found with both auditory and visual primes but only when word primes were used. On 
the basis of these data, Slowiaczek and Hamburger (1992) concluded that the effect results from a competition between the lexical representations of the primes and the targets.

In a subsequent study, Hamburger and Slowiaczek (1996) examined the contribution of strategic factors in initial overlap priming. They reported a reliable inhibitory effect with a three-phoneme overlap only when the strategic factors were discouraged by a low proportion of related pairs $(21 \%)$ and a short $(50 \mathrm{~ms})$ interstimulus interval (ISI). In contrast, in a condition intended to maximize strategic factors by a high proportion of related pairs $(75 \%)$ and a long $(500 \mathrm{~ms})$ ISI, the inhibition effect was negligible, thus indicating that strategic processes do not cause inhibitory priming effects but, rather, counteract them. Despite this observation, it was claimed that Hamburger and Slowiaczek (1996) findings of inhibition when primes and targets shared three phonemes did not reflect a "true" lexical competition effect. Rather, it would be the result of response biases developed by participants when they became aware of the presence of related prime-target pairs. In a replication of Hamburger and Slowiaczek (1996) experiment, Goldinger (1999) observed that RTs on the target words preceded by unrelated primes became slower as the experiment progressed. This slow-down on the control trials was taken as evidence that participants develop strategic processes to maximize performance on the related trials (Posner and Snyder 1975,see also Goldinger et al. 1992). Although the RT cost in the control condition was larger with a high proportion of related trials $(75 \%)$ and a long ISI $(500 \mathrm{~ms})$, it was also observed with a low proportion of related trials $(21 \%)$ and a short ISI $(50 \mathrm{~ms})$. Hence, according to Goldinger, the inhibitory priming effect should not be considered as an accurate picture of lexical competition, because it co-occurs with evidence for response biases. In a reanalysis of Hamburger and Slowiaczek (1996) data, Hamburger and Slowiaczek (1999) also showed that biases were reduced but not eliminated by the use of a low proportion of related pairs. Nonetheless, they maintained that the three-phoneme overlap inhibition reflects competition between the lexical representations of the primes and the targets. This is because inhibition is stronger when strategic biases are weaker, thus making it unlikely that response biases cause inhibitory priming effects. ${ }^{1}$

The lexical locus of the inhibitory priming effect was ascertained by another study of Radeau et al. (1995) in which the relative frequency of primes and targets was manipulated. French monosyllabic words sharing two out of three phonemes (e.g., bourg /bur/-boule /bul/) were used and participants performed a shadowing task. In contrast to Slowiaczek and Hamburger (1992), they reported that an initial overlap of two phonemes lead to inhibition, but only when the primes were less frequent than the targets. No effect was found when the primes were more frequent than the targets. Because the inhibitory priming effect varies as a function of prime-target relative frequency, that is, a lexical factor, Radeau et al., as Slowiaczek and Hamburger (1992), concluded that the effect comes from automatic competition between the lexical representations of the primes and the targets. The same conclusion was also drawn from a recent study by Dufour and Peereman (2003a) in which neighborhood density was manipulated. Using monosyllabic prime - target pairs and the shadowing task, Dufour and Peereman reported an inhibitory priming effect for words which come from sparse neighborhoods but not for words which come from dense neighborhoods. The observation that the neighborhood density influences the size of the inhibitory priming effect suggests again that the effect reflects, at least in part, lexical processing.

As discussed above, inhibitory priming effects can be readily explained within the framework of models that postulate intra-level inhibition. For example, although the TRACE model (McClelland and Elman 1986) has not yet been developed to simulate priming

1 Pitt and Shoaf (2002) more recently claimed that the inhibition observed with an initial overlap is the result of participants' surprise when they encounter the first related prime-target pairs. We will return to this suggestion later when considering the data of the present study. 
effects, all activated word units inhibit each other as a function of their activation levels. The more a word is activated, the more it sends out inhibition to other candidates. According to Slowiaczek and Hamburger (1992), inhibitory priming effects are occasioned during target presentation. Since the prime word is re-activated by the phonemes that it shares with the target, its level of activation increases sufficiently to strongly compete with the target word. In this perspective, the stronger inhibitory priming effect for words which come from sparse neighborhoods than for words which come from dense neighborhoods could be explained as follows. During the processing of the target word, the prime itself receiving inhibition from lexical competitors, it should be less competitive when reactivated among a large set of candidates, and thus should not act as a strong competitor of the target. Although such an account of the inhibitory priming effect is generally adopted (Dufour and Peereman (2003a,b); Monsell and Hirsh (1998); Slowiaczek and Hamburger $(1992))^{2}$, an alternative view would be to consider that conscious identification of the prime word causes inhibition of the target word, therefore slowing down its subsequent identification. This possibility has been envisaged by Segui and Grainger (1990) to explain inhibitory priming effects in the visual modality with unmasked primes. In this perspective, prime words should suffer more from lexical competition when similar to many other words, and they should therefore be less efficient to inhibit lexical competitors including the target words.

In a recent study, Dufour and Peereman (2003b) examined the effect of the number of mismatching phonemes occurring at the end of words, on the magnitude of the competition effect between primes and targets. Such an investigation was motivated by conflicting results between Slowiaczek and Hamburger (1992) and Radeau et al. (1995)'s studies in which a two-phoneme overlap led to inhibition in the second study but not in the first one. In a shadowing task, Dufour and Peereman reported that an inhibitory priming effect systematically occurred even in case of a reduced initial overlap, whenever the primes mismatched the targets on the last phoneme. When the primes mismatched the targets on the last two phonemes, no inhibitory priming effect emerged. Hence, as in Radeau et al. (1995)'s study, an inhibitory priming effect was found with prime-target pairs sharing the first two phonemes but, only if the primes mismatched the targets on the last phoneme (e.g., bol /bol/-botte /bot/). Dufour and Peereman also reported that an initial overlap of three phonemes was not sufficient to cause an inhibitory priming effect when the primes mismatched the targets on the last two phonemes (e.g., baguette /bag $\epsilon \mathrm{t} /$ - bagage /bagaj/). Together, these findings suggest that the effectiveness of a prime word to inhibit target recognition is dependent on a weak mismatch with the target word.

To sum up, competition effects between primes and targets overlapping by their first phonemes occur provided that the primes mismatch the targets on only one phoneme. The present research follows Dufour and Peereman (2003b)'s study and examines whether the position of the mismatching phoneme has an impact on the magnitude of the inhibitory priming effect. Given the sequential nature of the speech signal, one might expect that the later the mismatch between the prime and the target occurs, the stronger the competition should be during target processing, since in this case the prime word should be re-activated until the final phonemes of the targets are processed. As an example, consider the target word VILLAGE/vilaj/ primed by the word VIRAGE/viraj/. During the processing of the target word VILLAGE/vilaj/, the

\footnotetext{
2 The observation of stronger inhibitory priming effects with low frequency primes does not necessarily exclude the explanation proposed by Slowiaczek and Hamburger (1992) that inhibition operates during target presentation. Indeed, according to the NAM model, frequency is not coded at the resting level of word units but acts in biasing decision processes. Because decisions would be made less quickly for low-frequency than for high-frequency primes, this model predicts that low-frequency primes should produce more inhibition, since they begin to return to a resting level later than high-frequency primes do (see Luce et al. 1990, 2000).
} 
prime VIRAGE /viraj/ should rapidly cease to increase in activation, once the /1/ phoneme of the target VILLAGE /vilaj/ is processed. The prime being less re-activated, it should not act as a strong competitor of the target word. In contrast, if we consider the target word BAGAGE /bagaj/ primed by the word BAGARRE /bagar/, the prime BAGARRE /bagar/ should be strongly re-activated during processing of the target word BAGAGE /bagaj/, since its activation will rise until the last phoneme of the target is processed. As a result a late mismatching prime should compete more strongly with the target and thus should act as a stronger competitor of the target word. The inhibitory priming effect should thus be of greater magnitude when the mismatching phoneme between the primes and the targets occurs at the end of words. Note that such a prediction conflicts with that derived from NAM (Luce et al. 1990) in which effective competitors consist of all of the words that differ from a target by a single phoneme, regardless of where the one-phoneme difference occurs. As a result, NAM predicts that the inhibitory power of a prime should not vary as a function of the position of the mismatching phoneme. The present study was undertaken to provide an empirical examination of these predictions.

Three experiments were carried out in order to examine whether variations in the position of the mismatching phoneme lead to variations in the competition effect between prime and target words. In each experiment, all related primes shared with the targets four out of five phonemes but mismatched the targets on either the final or the medial phoneme. The stimulus lists included a weak proportion of related prime-target pairs $(25 \%)$ to minimize the influence of strategic factors that could counteract the expected inhibitory effects (Hamburger and Slowiaczek 1996). A short (50 ms) ISI was used to prevent the residual activation of the prime from dissipating before target presentation. Because it had previously been observed that low-frequency primes produce more inhibition than high-frequency primes (Radeau et al. 1995, see also Luce et al. 2000, for a similar observation in phonetic priming), the less frequent of the words, in each of the prime-target pairs was always used as the prime. In Experiments $1 \mathrm{~A}$ and $1 \mathrm{~B}$, both the primes and the targets were presented auditorily. In Experiment 2 , the primes were presented visually and the targets auditorily. In each experiment, participants performed a shadowing task.

\section{Experiment 1A}

Method

\section{Participants}

Forty students at the University of Bourgogne participated in the experiment for course credits. All were native speakers of French and reported no hearing or speech disorders.

\section{Materials}

Two sets of 28 bisyllabic target words, five phonemes in length, were selected from BRULEX a lexical database for the French language (Content et al. 1990). In the first set, the related primes mismatched the targets on the last phoneme (e.g., bagarre /bagar/ - bagage /bagaj/). In the second set, the related primes mismatched the targets on the medial phoneme (virage /viraj/ - village /vilaj/). For each of the 56 target words, a bisyllabic control prime, five phonemes in length, that did not have the same initial or final phonemes as the target 
was selected. In average, the primes and the targets had their uniqueness point after the last phoneme. The primes and targets are provided in Appendix A.

Both sets of targets were matched for word frequency, with mean logarithmic frequencies of 3.47 for the final mismatch condition and 3.45 for the medial mismatch condition $(F(1,54)=0.04, P>.20)$. The mean logarithmic frequencies of related and control primes were 2.28 and 2.46, respectively, for the final mismatch condition $(F(1,54)=0.51, P>$ $.20)$. The corresponding respective values for the medial mismatch condition were 2.35 and $2.61(F(1,54)=1.59, P>.20)$. The average durations of the targets were 618 and $623 \mathrm{~ms}$ for the final and the medial mismatch conditions, respectively $(F(1,54)=0.05, P>.20)$. In the final mismatch condition, the average durations of related and control primes were 633 and $593 \mathrm{~ms}$, respectively $(F(1,54)=1.77, P=.19)$. In the medial mismatch condition, the corresponding respective values were 625 and $612 \mathrm{~ms}(F(1,54)=0.41, P>.20)$.

Because each target was paired with two different primes (related and control) and no participant was presented with the same target twice, two experimental lists were created. Each list included the 56 target words. Half of them were preceded by a related prime, and the other half by a control prime. The lists were counterbalanced so that each target was preceded by the two types of prime. To achieve a proportion of related prime-target pairs of $25 \%, 56$ filler trials without any relation between the primes and the targets were added to each list.

\section{Procedure}

The stimuli were recorded by a female native speaker of French on a digital audio tape recorder. The items were digitized at a sampling rate of $44 \mathrm{kHz}$ with 16-bit analog-to-digital recording. The participants were tested individually in a quiet room. The presentation of the items was controlled by a computer. RTs were collected via a voice key connected to the computer. The primes and the targets were presented over headphones at a comfortable sound level. A $50 \mathrm{~ms}$ ISI separated the offset of the prime and the onset of the target. Each participant was asked to repeat the target as quickly and accurately as possible. The participant's response and the onset of the prime of the following trial were separated by a 2-sec silence. The naming latencies were measured from the onset of the target to the participant's response. Each participant was tested on only one experimental list and began the experiment with a block of 16 practice trials.

\section{Results and Discussion}

Four items (two in each of the mismatch conditions) were excluded from the analyses because of problems in the recording of these stimuli. For each participant, incorrect responses and RTs longer than 1,300 ms were removed from the analyses. Adopting these criteria only $1.11 \%$ of the data was rejected. The mean RTs and error rates in each condition are presented in Table 1. Because few errors occurred, analyses were performed on RTs only. Analyses of variance (ANOVAs) by participants $(F 1)$ and by items $(F 2)$ were conducted with prime type (related, control) and mismatch position (final, medial) as variables.

The main effect of mismatch position was significant by participants $\left(F_{1}(1,39)=12.54\right.$, $P<.01)$ but not by items $\left(F_{2}(1,50)=0.54, P>.20\right)$. The main effect of prime type was significant by participants $\left(F_{1}(1,39)=9.99, P<.01\right)$ and approached significance by items $\left(F_{2}(1,50)=3.42, P=.07\right)$. The interaction between prime type and mismatch 
Table 1 Mean reaction times (in $\mathrm{ms}$ ) and error rates (in \%) for related and control primes as a function of mismatch position in Experiment 1A

Standard deviations are given in parentheses

\begin{tabular}{lll}
\hline & Prime type & \\
\cline { 3 - 3 } & Related & Control \\
\hline Mismatch Position & & \\
Final & & $823(102)$ \\
RT & $854(98)$ & 0.38 \\
Error & 0 & \\
Medial & & $833(99)$ \\
RT & $819(106)$ & 0.77 \\
Error & 1.35 & \\
\hline
\end{tabular}

position was highly significant both by subjects $\left(F_{1}(1,39)=52.33, P<.001\right)$ and by items $\left(F_{2}(1,50)=23.93, P<.001\right)$.

Planned comparisons were conducted to assess the effect of priming within each mismatch position. An inhibitory priming effect was observed only in the final mismatch condition. Responses to targets were $31 \mathrm{~ms}$ slower when they were preceded by the related primes in comparison with the control primes. This effect was highly significant both by subjects $\left(F_{1}(1,39)=52.87, P<.001\right)$ and by items $\left(F_{2}(1,50)=22.71, P<.001\right)$. In contrast, a facilitatory priming effect was observed in the medial mismatch condition. Responses to targets were $14 \mathrm{~ms}$ faster when they were preceded by the related primes in comparison with the control primes. This effect was significant both by subjects $\left(F_{1}(1,39)=13.05, P<.001\right)$ and by items $\left(F_{2}(1,50)=4.63, P<.05\right)$.

To summarize, Experiment $1 \mathrm{~A}$ indicates that competition effect occurs when the primes mismatch the targets on the final phoneme (bagarre /bagar/ - bagage /bagaj/). In contrast, the prior presentation of a prime (virage /viraj/) that mismatches the target (village /vilaj/) on the medial phoneme facilitates the subsequent processing of the target word. Before discussing more fully the cause of the facilitation in the medial mismatch condition, we conducted Experiment 1B to ensure that the effect was not caused by anticipatory strategy of the end of the words. Indeed, it could be that upon hearing the first three phonemes /vil/ of the target word /vilaj/, participants strategically completed the end of the target word by that of the prime /viraj/, thus leading to shorter shadowing latencies.

\section{Experiment 1B}

In Experiment 1B, foils consisting of prime and target words that mismatched on both the medial and final phonemes (moquette $/$ mok $\epsilon \mathrm{t} /$ - molaire $/ \mathrm{mol} \in \mathrm{r} /$ ) were used. Foils like this should discourage participants from planning the offset of the targets on the basis of the offset of the primes. Indeed, if the participants were to assume that stimuli differing on the medial phoneme in fact go on to share their offsets, they would assume that the target $/ \mathrm{mol} \in \mathrm{r} /$ continues as the prime /mok $\epsilon \mathrm{t} /$ does and would thus incorrectly give as response the word $/ \mathrm{mol} \epsilon \mathrm{t} /$. Experiment 1B was the same as Experiment 1A, except that $12.5 \%$ of the trials in the stimulus lists were foils, which corresponds to the proportion of trials that mismatched in the medial phoneme. If the facilitation observed in the medial mismatch condition was purely the result of strategic processes, no effect should emerge when foils are included in the experiment. 
Table 2 Mean reaction times (in $\mathrm{ms}$ ) and error rates (in \%) for related and control primes as a function of mismatch position in Experiment 1B

Standard deviations are given in parentheses

\begin{tabular}{lll}
\hline & Prime type & \\
\cline { 3 - 3 } & Related & Control \\
\hline Mismatch Position & & \\
Final & & $745(84)$ \\
RT & $784(77)$ & 0.63 \\
Error & 0.21 & \\
Medial & & $761(87)$ \\
RT & $747(90)$ & 0.21 \\
Error & 0.84 & \\
\hline
\end{tabular}

Method

\section{Participants}

Thirty-four students at the University of Geneva participated in the experiment for course credits. All were native speakers of French and reported no hearing or speech disorders.

\section{Materials}

The materials were the same as in Experiment 1A, except that 14 of the unrelated filler trials of Experiment 1A were replaced by filler items producing foil trials. Foils consisted of primetarget pairs such as $/$ mok $\epsilon \mathrm{t} / \mathrm{-} / \mathrm{mol} \in \mathrm{r} /$ that mismatched on both the medial and final phonemes. They were selected in such a way that a word was always formed when replacing the final phonemes of the targets by that of the primes (i.e., the word /mol $\mathrm{t} /$ for the prime-target pair $/$ mok $\epsilon \mathrm{t} / \mathrm{-} / \mathrm{mol} \epsilon \mathrm{r} /)$. The foil trials used in the experiment are listed in Appendix B. All items were recorded using the same procedure as in Experiment 1A. The average durations of the targets were 620 and $627 \mathrm{~ms}$ for the final and the medial mismatch conditions, respectively. In the final mismatch condition, the average durations of related and control primes were 631 and $602 \mathrm{~ms}$, respectively. In the medial mismatch condition, the corresponding respective values were 628 and $613 \mathrm{~ms}$. All other aspects of the procedure remained the same.

\section{Results and Discussion}

The RT data were analyzed according to the same criteria as in Experiment 1A. Less than 1\% of the data were rejected. The mean RTs and error rates in each condition are presented in Table 2. Because few errors occurred, only RTs were submitted to ANOVAS. Note that the error rate on the foil trials was extremely low $(0.42 \%)$. One participant produced "bol $\in \mathrm{n}$ " in response to "pol $\epsilon$ " and one produced "desãt" in response to "desãs". Removing the participant whose response corresponded to what would be expected in case of strategic completion of the offset of the targets by that of the primes, the same pattern of results as follows was observed.

The main effect of mismatch position was significant by participants $\left(F_{1}(1,33)=9.85\right.$, $P<.01)$ but not by items $\left(F_{2}(1,54)=0.53, P>.20\right)$. The main effect of prime type was significant both by participants $\left(F_{1}(1,33)=17.18, P<.001\right)$ and by items $\left(F_{2}(1,54)=\right.$ $10.96, P<.01)$. The interaction between prime type and mismatch position was highly 
significant both by subjects $\left(F_{1}(1,33)=45.23, P<.001\right)$ and by items $\left(F_{2}(1,54)=\right.$ 58.21, $P<.001)$.

Planned comparisons were conducted to assess the effect of priming within each mismatch position. An inhibitory priming effect was observed only in the final mismatch condition. Responses to targets were $39 \mathrm{~ms}$ slower when they were preceded by the related primes in comparison with the control primes. This effect was highly significant both by subjects $\left(F_{1}(1,33)=74.03, P<.001\right)$ and by items $\left(F_{2}(1,54)=59.85, P<.001\right)$. Again, a facilitatory priming effect was observed in the medial mismatch condition. Responses to targets were $14 \mathrm{~ms}$ faster when they were preceded by the related primes in comparison with the control primes. This effect was significant both by subjects $\left(F_{1}(1,33)=6.75, P<.05\right)$ and by items $\left(F_{2}(1,54)=9.33, P<.01\right)$. Note that the magnitude of the facilitation effect was exactly the same as in Experiment 1A. Hence, it appears that the magnitude of the effect was not altered by the inclusion of foils in the experiment. As a consequence, the facilitation effect in the medial mismatch condition is not likely to be due to strategic anticipation of the end of words.

To summarize, Experiments $1 \mathrm{~A}$ and $1 \mathrm{~B}$ indicate that competition effect occurs when the primes mismatch the targets on the final phoneme (bagarre /bagar/ - bagage /bagaj/), an observation similar to previous findings (Dufour and Peereman 2003b; Radeau et al. 1995; Slowiaczek and Hamburger 1992). However, no competition effect was observed when the primes mismatch the targets on a medial phoneme (virage/viraj/ - village /vilaj/). In contrast, the prior presentation of a prime that mismatches the target on the medial phoneme facilitates the subsequent processing of the target word. Because primes that mismatch the targets on the medial phoneme necessarily share the final phonemes with the targets, it might be that the facilitation results from rime overlap (virage /viraj/ - village /vilaj/). Indeed, as we have mentioned above, numerous studies have shown facilitatory priming effects when primes and targets do not share the onset but have their final phonemes in common (Dumay et al. 2001; Monsell and Hirsh 1998; Norris et al. 2002; Radeau et al. 1995; Slowiaczek et al. 2000; Spinelli et al. 2001). Final overlap facilitation is generally observed only when both the primes and the targets are presented auditorily, but it does not emerge under cross-modal presentation either when the prime is spoken and the target is visual (Radeau et al. 1994; Spinelli et al. 2001) or the reverse (Dumay et al. 2001). Such an observation suggests that final overlap facilitation occurs rather early in the course of target processing. Most authors have therefore assumed that final overlap facilitation reflects the repeated activation of prelexical representations (i.e., rime, syllable), that is, the mental representations that mediate the mapping between the acoustic signal and the mental lexicon (Dumay et al. 2001; Norris et al. 2002; Radeau et al. 1995; Slowiaczek et al. 2000; Spinelli et al. 2001). ${ }^{3}$ The processing of the target is facilitated because its recognition involves the use of prelexical units that were already activated during prime processing. Hence, in the case of a medial mismatch, it remains possible that prelexical facilitation due to rime overlap dominates and overcomes the inhibition resulting from competition between the lexical representations of the primes and the targets. In Experiment 2, the effect caused by a divergence on the medial phoneme was re-examined with primes presented visually rather than auditorily. Indeed, in the light of the results reported in the literature, such a manipulation should make it possible to counteract the facilitation effect caused by offset overlap.

\footnotetext{
3 The logic underlying cross-modal presentation is that an effect with a pre-lexical locus should not be observed when tested in different modalities, because the sublexical units activated by the primes could not be reused to speed up the processing of the target. In contrast, an effect reflecting activation of the lexical representations should be modality independent and should be of similar magnitude when tested in different modalities.
} 


\section{Experiment 2}

Method

\section{Participants}

Thirty-six students were recruited from the same pool as in Experiment 1B. They had normal and corrected to normal vision. None of them had taken part in Experiment 1B.

\section{Materials and Procedure}

The materials were the same as in Experiment 1A. The procedure was identical to that used in Experiments 1A and 1B except that the primes were visually displayed for $600 \mathrm{~ms}$, which corresponds roughly to the mean duration of auditory primes in the previous experiments. All other aspects of the procedure remained the same.

\section{Results and Discussion}

Two items in the medial mismatch condition that gave rise to an error rate of more than $30 \%$ were excluded from the analyses. The RT data were analyzed according to the same criteria as in Experiment 1A and 1B. The percentage of rejected data was 2.16. The mean RTs and Error rates in each condition are presented in Table 3. Because few errors occurred, only RTs were submitted to ANOVAS.

The main effect of mismatch position was significant neither by participants $\left(F_{1}(1,35)=\right.$ $0.13, P>.20)$ nor by items $\left(F_{2}(1,52)=0.11, P>.20\right)$. The main effect of prime type was not significant both by participants $\left(F_{1}(1,35)=0.45, P>.20\right)$ and by items $\left(F_{2}(1,52)=0.02, P>.20\right)$. The interaction between prime type and mismatch position was highly significant both by subjects $\left(F_{1}(1,35)=26.99, P<.001\right)$ and by items $\left(F_{2}(1,52)=\right.$ 20.55, $P<.001$ ).

Planned comparisons were conducted to assess the effect of priming within each mismatch position. An inhibitory priming effect was observed only in the final mismatch condition. Responses to targets were $33 \mathrm{~ms}$ slower when they were preceded by the related primes in comparison with the control primes. This effect was significant both by subjects $\left(F_{1}(1,35)=27.66, P<.001\right)$ and by items $\left(F_{2}(1,52)=11.28, P<.01\right)$. Again, a facilitatory priming effect was observed in the medial mismatch condition. Responses to targets

Table 3 Mean reaction times (in $\mathrm{ms}$ ) and error rates (in \%) for related and control primes as a function of mismatch position in Experiment 2

Standard deviations are given in
parentheses

\begin{tabular}{lll}
\hline & Prime type & \\
\cline { 2 - 3 } & Related & Control \\
\hline $\begin{array}{l}\text { Mismatch Position } \\
\text { Final }\end{array}$ & \\
RT & $902(125)$ & \\
Error & 1.39 & $869(127)$ \\
Medial & & 1.39 \\
RT & $870(120)$ & $897(123)$ \\
Error & 1.71 & 1.07 \\
\hline
\end{tabular}


were $27 \mathrm{~ms}$ faster when they were preceded by the related primes in comparison with the control primes. This effect was significant both by subjects $\left(F_{1}(1,35)=9.17, P<.01\right)$ and by items $\left(F_{2}(1,52)=9.36, P<.01\right)$. Hence as in Experiment 1 , the competition effect occurs only when the primes mismatch the targets on the last phoneme.

What is the cause of the facilitation effect in case of a medial mismatch? As discussed above, the facilitation observed in Experiments 1A and 1B with auditory prime and target words likely results from offset overlap. Compatible with Norris et al. (2002) observation, Experiment 1B shows that the magnitude of the final overlap facilitation in a shadowing task, is not influenced by the presence of foils. Such an observation thus provides new evidence that automatic effects can be observed, at least in a shadowing task, when primes overlap with the final phonemes of targets (see Norris et al. 2002). However, it is unlikely that the facilitation effect observed in Experiment 2 with visual primes was caused by offset overlap. Indeed, as mentioned above, studies have shown that final overlap facilitation did not occur under cross-modal presentation (Dumay et al. 2001; Radeau et al. 1994; Spinelli et al. 2001). Moreover, it has been shown that the effect does not vary as a function of lexical factors such as the lexicality of the primes and the targets (Dumay et al. 2001; Slowiaczek et al. 2000; Spinelli et al. 2001; see also, Norris et al. 2002) or the prime-target relative frequency (Radeau et al. 1995). Together, these observations suggest that final overlap facilitation occurs at a prelexical level and does not involve activation of lexical representations. The fact that the primes were visually presented suggests that the effect in Experiment 2 occurs at a lexical level. Hence, one possibility is that the facilitation in Experiment 2 results from activation of orthographic neighbors during prime processing. To test this hypothesis, the target words were split into two groups according to their orthographic distance with the primes. Eleven prime-target pairs were close orthographic neighbors and thus differed by only one letter (e.g., conique-comique) and 15 were distant orthographic neighbors and differed by more than one letter (e.g., barème-baptême). An ANOVA on the item means was conducted with prime type (related, control) and orthographic distance (close, distant) as variables. ${ }^{4}$ The interaction between prime type and orthographic distance was nearly significant $(F(1,24)=3.80, P=.06)$ and showed that the facilitatory priming effect was stronger for close than for distant orthographic neighbors. Comparisons revealed that close orthographic words were responded to $48 \mathrm{~ms}$ faster when they were preceded by related primes in comparison with control primes $(F(1,24)=15.11, P<.001)$. Also, distant orthographic words were responded to $15 \mathrm{~ms}$ faster when they were preceded by related primes in comparison with control primes. The difference, however, did not reach significance $(F(1,24)=2.38, P=.14)$. Together, these observations indicate that the facilitation effect in Experiment 2 with visual primes is due to preactivation of the target words, in particular those that were close orthographic neighbors, during prime presentation, thus speeding up their subsequent processing. As can be expected, given the auditory presentation of the prime words, both word sets produced similar priming effects (20 and $13 \mathrm{~ms}$, for close and distant words, respectively) in Experiments 1. Note also that there was no sign of inhibition in the medial mismatch condition, even for distant orthographic prime words. Hence the inhibitory priming effect appears greatly dependant on a final mismatch between the primes and the targets.

4 The two sets of words were matched on both frequency and duration. 


\section{Discussion}

In a recent study in which the number of mismatching phonemes occurring at the end of words was manipulated, Dufour and Peereman 2003b reported that inhibitory priming effects systematically occur provided that the primes mismatch the targets on only one phoneme. The present study extends our previous observation and examines whether variations in the position of the mismatching phoneme lead to variations regarding the inhibitory influence of the prime on target word recognition. An inhibitory priming effect was systematically found when the primes mismatched the targets on the final phoneme. No competition effect was found when the primes mismatched the targets on the medial phoneme. In contrast, the prior presentation of a prime that mismatched the target on the medial phoneme facilitated the subsequent processing of the target word. The inhibition effect in case of a final mismatch and the facilitation effect in case of a medial mismatch were found under both unimodal (auditory-auditory) and cross-modal (visual-auditory) presentation. Together, these findings suggest that the effectiveness of a prime word to inhibit target recognition is dependent on a final mismatch with the target word.

Pitt and Shoaf (2002) recently stated that the inhibition found with primes and targets overlapping by their first phonemes reflects a surprise effect. In order to examine the contribution of response biases in phonological priming experiments, Pitt and Shoaf compared the magnitude of the priming effects at various points during the experimental session. They reported that the size of the inhibitory priming effect decreased between the beginning and the end of the experiment. A strong inhibitory priming effect occurred at the beginning of the experiment, but no inhibition was observed at the end of the experiment even in a condition intended to minimize strategic processes (with $10 \%$ of related prime-target pairs). To account for the data, Pitt and Shoaf (2002) claimed that inhibitory priming effects are due to participants' surprise that arises when they encounter the first related trial. Moreover, they suggest that priming effects are distorted by strategic anticipations that participants develop in order to maximize fast responses on related trials, once the phonemic overlap between primes and targets is noticed. Such an account was motivated by the observation that RTs on control trials increased and those on related trials decreased over the course of the experiment, a reliable indicator that response strategies were at work (Posner and Snyder 1975). It is however unlikely that the present inhibition results from participants' surprise. Indeed, related trials were included in the training session (four related trials out of a total of 16) so that any surprise effect should be manifested during the training session, not during the experimental session. Moreover, it has been found that inhibitory priming effects vary as a function of lexical factors such as the lexicality (Slowiaczek and Hamburger 1992) or frequency (Radeau et al. 1995) of the prime and the neighborhood density of the target words (Dufour and Peereman 2003a). At first sight, there is no reason to believe that the size of a surprise effect should vary as a function of lexical factors. Hence, it seems that an explanation of inhibitory effects in terms of an automatic competition between lexical candidates is the more appropriate.

The basic finding of this study is that a competition effect between primes and targets is observed provided that the mismatching phoneme occurs at the end of words. Inhibitory priming effects are predicted by models such as NAM (Luce et al. 1990) which do not postulate inter-word competition mechanism but in which the decision about the identity of the word depends on the ratio between the activation level of the target word to that of all other competitors. However, we believe that NAM cannot account for the modulation of the priming effect as a function of the mismatching phoneme position. Indeed, because NAM assumes that effective competitors are those that differ from the targets by a single phoneme 
in any position, inhibitory priming effect should have been observed whatever the position of the mismatching phoneme.

The observation of an inhibitory priming effect is compatible with models such as TRACE (McClelland and Elman 1986) and Shortlist (Norris 1994) that include inter-word competition mechanism. In TRACE, all the lexical nodes are potential candidates for recognition, continuously increasing or decreasing in activation as a function of their match with the incoming signal. The degree to which a competitor tries to inhibit the target word is a function of its activation level. The more a competitor is activated, the more inhibition the target word will receive. Because in TRACE, competitors are activated in proportion to their matches with the incoming signal, an inhibitory priming effect should be predicted for both the medial and the final mismatch conditions, since in the two conditions primes and targets overlapped by the same number of phonemes (four out of five phonemes). Nonetheless, simulation works with the TRACE model (Frauenfelder and Peters 1998) showed that the recognition of the target word SURPLUS was more affected by competitors that match the target on the first two phonemes (e.g., SUBTLE) than those that match the target on the second and third phonemes but mismatch it on the first one (e.g., TURBINE). Compatible with our findings, such an observation indicates that the activation of lexical candidates suffers more from early than from late mismatching information. Simulation works are required to have precise predictions regarding TRACE's behaviour in case of a single mismatching phoneme occurring at various positions.

An interesting feature of the Shortlist model is that mismatching candidates have their activation decreased through bottom-up inhibition. In accordance with this feature, the lack of inhibitory priming effect in case of a medial mismatch suggests that lexical candidates are quickly deactivated once they do not longer match the incoming signal. Our results can thus be easily accounted for by models like Shortlist (Norris 1994) that postulate bottom-up inhibition, in addition to an inter-word inhibition mechanism. Through bottom-up inhibition, the earlier the mismatch between the target and its competitor occurs, the faster the activation of the competitor is turned off, thus strongly reducing its inhibitory influence during target word processing. The assumption that the mismatching candidates have their activation decreased via bottom-up inhibition is supported by recent studies using different experimental paradigms, such as the cross-modal fragment priming paradigm (Cutler and van Donselaar 2001; Soto-Faraco et al. 2001) and the phoneme monitoring task (Frauenfelder et al. 2001). These findings, together with our results, suggest that both bottom-up inhibition and lexical competition are involved in the word recognition process.

Unlike the models discussed above, the Distributed Cohort Model (DCM; Gaskell \& Marslen-Wilson 1997) depicts competition as interference between multiple distributed representations. In contrast to localist models in which each word has its own separate node, in a distributed system all words are represented on the same nodes. As a result, only one word can be perfectly represented at any one time. The activation of a word is considered to be inversely related to the distance between the output produced by the network and the expected pattern of activation, so that a small distance indicates a high degree of activation. Interestingly, it has been shown that in DCM, the distance between the output produced by the network and the expected pattern of activation increases with the number of activated candidates. It is only when the uniqueness point of the word is reached that the distance from the target word approach the minimum distance of zero. Because DCM deals with the sequentiality of the lexical mapping process, it also predicts a greater competition effect from words that match the target word until its last phoneme. 
In conclusion, the present study indicates that the position of the mismatching phoneme between the primes and the targets is an important factor in determining the magnitude of the competition effect. We believe that the present research brings further constraints on what defines an effective competitor.

\section{Appendix A}

\section{See Table 4}

Table 4 Experimental stimuli used in Experiments 1A, 1B and 2

\begin{tabular}{|c|c|c|c|c|c|}
\hline \multicolumn{3}{|c|}{ Final mismatch } & \multicolumn{3}{|c|}{ Medial mismatch } \\
\hline Targets & Related primes & Control primes & Targets & Related primes & Control primes \\
\hline bagage & bagarre & cornet & colonne & cochonne & farine \\
\hline canal & canard & légume & comique & conique & palace \\
\hline semaine & semelle & crayon & colline $^{\mathrm{a}, \mathrm{b}}$ & copine & vidange \\
\hline colère & collège & bétise & pétale & pédale & vernis \\
\hline métal & méthane & blouson & parade & passade & frelon \\
\hline montagne & montage & trousseau & gamelle & gazelle & perruche \\
\hline banale & banane & méduse & comète & coquette & pirate \\
\hline caresse & carême & flocon & cabine & canine & girafe \\
\hline cigare & cigale & volcan & boutique & bourrique & compote \\
\hline malaise $^{\mathrm{a}}$ & mallette & plumeau & cachette & canette & baril \\
\hline police & polir & dicton & défense & dépense & lunette \\
\hline valise & valide & poireau & désir & délire & colombe \\
\hline baraque $^{\mathrm{a}}$ & barrage & piéton & machine & marine & dentelle \\
\hline bataille & bâtard & livret & figure & fissure & salade \\
\hline conseil & concert & légende & liquide & livide & contrat \\
\hline famille & famine & marteau & mission & million & cerveau \\
\hline manège & manette & pruneau & modèle & motel & caniche \\
\hline minute & minus & capuche & cheville & chenille & support \\
\hline cantique & cantine & rapace & racine & radine & module \\
\hline coquille & coquine & briquet & remords & records & goudron \\
\hline carosse & carotte & cisaille & retard & renard & culotte \\
\hline baleine & balèze & pétanque & légion & lésion & parure \\
\hline coutume & couture & garage & sourire & soupir & local \\
\hline baroque & baronne & gradin & cadence & carence & biberon \\
\hline pareil & paresse & malice & concret $^{\mathrm{a}, \mathrm{b}}$ & congrès & buisson \\
\hline patron & patrie & symbole & village & virage & palette \\
\hline tonnerre & tonnelle & frigo & baptême & barème & gourdin \\
\hline galère & galètte & calmant & bottine & bobine & carafe \\
\hline
\end{tabular}

a Items excluded from the analyses in Experiment $1 \mathrm{~A}$

${ }^{\mathrm{b}}$ Items excluded from the analyses in Experiment 2 


\section{Appendix B}

\section{See Table 5}

Table 5 Foil trials used in Experiment 1B. The incorrect responses that participants would give if they anticipate the offset of the target words on the basis of the offset of the primes are shown in parentheses

\begin{tabular}{ll}
\hline Targets & Primes \\
\hline batisse (batir) & bannir \\
salive (salir) & saphir \\
molaire (molette) & moquette \\
chauffard (chauffage) & chômage \\
retouche (retours) & recours \\
sévices (sévir) & saisir \\
civil (civique) & cynique \\
décence (descente) & démente \\
pollen (polaire) & poker \\
poulaine (poulette) & poussette \\
soleil (solaire) & sommaire \\
tirade (tirage) & tissage \\
nautique (notice) & novice \\
chérir (shérif) & chétif \\
\hline
\end{tabular}

\section{References}

Bard, E. G. (1990). Competition, lateral inhibition, and frequency: Comments on the papers of Frauenfelder and Peeters, Marslen-Wilson and others. In G. T. M. Altmann (Ed.), Cognitive models of speech processing: Psycholinguistic and computational perspectives, (pp. 185-210). Cambridge, MA: MIT Press.

Chéreau, C., Gaskell, M. G., \& Dumay, N. (2007). Reading spoken words: Orthographic effects in auditory priming. Cognition, 102, 341-360.

Content, A., Mousty, P., \& Radeau, M. (1990). BRULEX: Une base de données lexicales informatisée pour le français écrit et parlé. L'Année Psychologique, 90, 551-566.

Cutler, A., \& van Donselaar, W. (2001). Voornaam is not (really) a homophone: Lexical prosody and lexical access in Dutch. Language \& Speech, 44, 171-195.

Dufour, S., \& Peereman, R. (2003a). Inhibitory priming effects in auditory word recognition: When the target's competitors conflict with the prime word. Cognition, 88, B33-B44.

Dufour, S., \& Peereman, R. (2003b). Lexical competition in phonological priming: Assessing the role of phonological match and mismatch lengths between primes and targets. Memory and Cognition, 31, 1271-1283.

Dumay, N., Benraïss, A., Barriol, B., Colin, C., Radeau, M., \& Besson, M. (2001). Behavioral and electrophysiological study of phonological priming between bisyllabic spoken words. Journal of Cognitive Neuroscience, 13, 121-143.

Frauenfelder, U. H., \& Peters, G. (1998). Simulating the time course of word recognition: an analysis of lexical competition in TRACE. In J. Grainger \& A. Jacobs (Eds.), Symbolic/connectionist approaches to human cognition (pp. 102-145). Hillsdale, NJ: Lawrence Erlbaum Associates.

Frauenfelder, U. H., Scholten, M., \& Content, A. (2001). Bottom up inhibition in lexical selection: Phonological mismatch effects in spoken word recognition. Language and Cognitive Processes, 16, 583-607.

Gaskell, M. G., \& Marslen-Wilson, W. D. (1997). Integrating form and meaning: A distributed model of speech perception. Language and Cognitive Processes, 12, 613-656.

Goldinger, S. D. (1999). Only the Shadower knows: Comment on Hamburger \& Slowiaczek (1996). Psychonomic Bulletin and Review, 6, 347-351.

Goldinger, S. D., Luce, P. A., Pisoni, D. B., \& Marcario, J. K. (1992). Form-based priming in spoken word recognition: The roles of competition and bias. Journal of Experimental Psychology: Learning, Memory, and Cognition, 18, 1211-1238. 
Hamburger, M. B., \& Slowiaczek, L. M. (1996). Phonological priming reflects lexical competition. Psychonomic Bulletin \& Review, 3, 520-525.

Hamburger, M. B., \& Slowiaczek, L. M. (1999). On the role of bias in dissociated phonological priming effects: A reply to Goldinger (1999). Psychonomic Bulletin \& Review, 6, 352-355.

Luce, P. A., Goldinger, S. D., Auer E. T. Jr., \& Vitevitch, M. S. (2000). Phonetic priming, neighborhood activation and PARSYN. Perception \& Psychophysics, 62, 615-625.

Luce, P. A., Pisoni, D. B., \& Goldinger, S. D. (1990). Similarity neighborhoods of spoken words. In G. T. M. Altmann (Ed.), Cognitive models of speech processing: Psycholinguistic and computational perspectives (pp. 122-147). Cambridge, MA: MIT Press.

Marslen-Wilson, W. D. (1987). Functional parallelism in spoken word recognition. Cognition, 25, 71-102.

Marslen-Wilson, W. D., Moss, H. E., \& van Halen, S. (1996). Perceptual distance and competition in lexical access. Journal of Experimental Psychology: Human Perception and Performance, 22, 1376-1392.

McClelland, J. L., \& Elman, J. L. (1986). The TRACE model of speech perception. Cognitive Psychology, 18, $1-86$.

Monsell, S., \& Hirsh, K. W. (1998). Competitor priming in spoken word recognition. Journal of Experimental Psychology: Learning, Memory and Cognition, 24, 1495-1520.

Norris, D. (1994). SHORTLIST: A connectionist model of continuous speech recognition. Cognition, 52, 189-234.

Norris, D., McQueen, J. M, \& Cutler, A. (2002). Bias effects in facilitatory phonological priming. Memory and Cognition, 30, 399-411.

Pitt, M. A. \& Shoaf, L. (2002). Revisiting bias effects in word-initial phonological priming. Journal of Experimental Psychology: Human Perception and Performance, 28, 1120-1130.

Posner, M. I., \& Snyder, C. (1975). Facilitation and inhibition in the processing of signals. In P. M. A. Rabbit \& S. Dornic (Eds.), Attention and performance V (pp. 669-681). New York: Academic Press.

Radeau, M., Besson, M., Fonteneau, E., \& Castro, S. L. (1998). Semantic, repetition, and rime priming between spoken words: Behavioral and electrophysiological evidence. Biological Psychology, 48, 183-204.

Radeau, M., Morais, J., \& Dewier, A. (1989). Phonological priming in spoken word recognition: Task effects. Memory and Cognition, 17, 525-535.

Radeau, M., Morais, J., \& Segui, J. (1995). Phonological priming between monosyllabic spoken words. Journal of Experimental Psychology: Human Perception and Performance, 21, 1297-1311.

Radeau, M., Segui, J. \& Morais, J. (1994). The effect of overlap position in phonological priming between spoken words. Proceedings of the international conference on spoken language processing, (pp. 1419-1422). Yokohama, Japan.

Segui, J., \& Grainger, J. (1990). Priming word recognition with orthographic neighbors: Effects of relative prime-target frequency. Journal of Experimental Psychology: Human Perception and Performance, 16, 65-76.

Slowiaczek, L. M., \& Hamburger, M. B. (1992). Prelexical facilitation and lexical interference in auditory word recognition. Journal of Experimental Psychology: Learning, Memory and Cognition, 18, 1239-1250.

Slowiaczek, L. M., McQueen, J., Soltano, E. G., \& Lynch, M. (2000). Phonological representations in prelexical speech processing: Evidence from form-based priming. Journal of Memory and Language, 43, $530-560$.

Slowiaczek, L. M., Nusbaum, H. C., \& Pisoni, D. B. (1987). Phonlogical priming in auditory word recognition. Journal of Experimental Psychology: Learning, Memory and Cognition, 13, 64-75.

Slowiaczek, L. M., \& Pisoni, D. B. (1986). Effects of phonological similarity on priming in auditory lexical decision. Memory and Cognition, 14, 230-237.

Soto-Faraco, S., Sebastián-Gallés, N., \& Cutler, A. (2001). Segmental and suprasegmental mismatch in lexical access. Journal of Memory \& Language, 45, 412-432.

Spinelli, E., Segui, J., \& Radeau, M. (2001). Phonological priming in spoken word recognition with bisyllabic targets. Language and Cognitive Processes, 16, 367-392. 